\title{
Segementasi Nasabah Tabungan Pada BMT XXX dengan Metode Fuzzy C Means dan Model RFM
}

\author{
Arief Soma Darmawan, Devi Sugianti, Anas Syaifudin \\ Email: ariefsoma24@gmail.com \\ STMIK Widya Pratama Pekalongan
}

\begin{abstract}
Abstrak
Setiap perusahaan akan berlomba lomba untuk meningkatkan pelayanan kepada pelanggan, agar pelanggan tidak berpindah ke pesaing. BMT XXX juga tidak menginginkan nasabahnya berpindah ke pesaing. Pada tahun 2019 nasbah BMT XXX mencapai 4882 nasabah, akan tetapi yang aktif melakukan transaksi penabungan hanya 1392 nasabah. BMT mengalami kesulitan dalam menginterpretasikan data, karena data yang tersaji dalam bentuk manual. Untuk membantu BMT dalam mengelompokkan nasabah yang potensial menggunakan metode fuzzy C Means dan model RFM (Recency, Frequency, dan Monetary). Metode Fuzzy C means digunakan karena dapat menggelompokkan data yang lebih besar dan lebih kokoh pada data oulier, dalam menentukan cluster atau kelompok dengan derajat keanggataan. Langkah langkah metode penelitian yang dilakukan adalah pengumpulan data, pengolahan data, metode yang diusulkan, eksperimen metode, validasi hasil atau pengujina. Hasil pengujian dengan Davies Bouldin Index diperoleh 0,464 dengan jumlah klaster sebanyak 6. Dengan kelas nasbah superstar sebanyak 79 nasabah, golden sebanyak 462 nasabah, typical customer 124 nasabah, occantional customer sebanyak 271 nasabah, everyday sopper 239 nasabah, dormant cusomer 217 nasabah. Dengan adanya data tersebut dapat digunakan oleh BMT XXX pengambilan keputusan dalam hal menentukan strategi marketing untuk meningkatkan pelanggan agar pelanggan selalu aktif melakukan penabungan
\end{abstract}

Kata Kunci : Segementasi nasabah, fuzzy c means, RFM

\section{Pendahuluan}

Perusahaan modern sekarang berfokus pada strategi yang mengutamakan pelanggan dari pada mengutamakan produk. Karena setiap perusahaan di tuntut agar siap menghadapi para pesaing dengan perusahaan lain. [1]. Karakteristik pelanggan harus dipertimbangkan oleh perusahaan untuk informasi pengembangan produk yang sesuai dengan keinginan pelanggan [2]. Perusahaan harus melindungi pelanggan yang potesial agar tidak berpindah ke pesaing. Dalam mempertahankan pelanggan yang dimiliki oleh perusahaan, merupakan hal yang sangat penting. [3]. Nasabah dalam lembaga keuangan mikro mempunyai nilai yang berbeda, tantangan yang dihadapai adalah pengetahuan memahami perbedaan nasabah yang potensial agar nasabah loyal terhadap perusahaan [4]

Pada BMT XXX memiliki jumlah nasabah sebanyak 4882 pada tahun 2019. Nasabah setiap tahunnya selalu meningkat, akan tetapi transaksi pada tahun 2019 yang aktif melakukan penabungan sebesar 1392 nasabah. Untuk mengidentifikasi nasabah yang potensial BMT XXX mengalami kesulitan karena menggunakan data secara manual, maka membutuhkan waktu yang lama untuk dapat mengiterpretasikan data tersebut. Untuk mengidentifikasi pelanggan dan menciptakan pengetahuan pelanggan maka bisa menggunakan proses CRM. Perbankan dipaksa untuk memperbaiki kinerja untuk meningkatkan palayanan pelanggan [5]. Ujung tombak dari suatu bisnis adalah menjalin hubungan baik dengan pelanggan karena sebagai salah satu stakeholders, itu adalah konsep dari CRM [6]. Data mining dapat menyelesaikan pengelompokkan nasabah. Data mining dapat mengekstraksi atau penggalian data untuk mendapatkan infromasi yang berguna untuk penggambilan keputusan bisnis [7]. Pengelompokkan nasabah potensial dengan menggunakan algoritma fuzzy $C$ menas. Fuzzy $C$ menas dipilih karena bersifat samar, dimana satu objek dapat menjadi anggota di beberapa cluster serta batasan cluster. Fuzzy C Means memiliki derajat keanggotaan antra 0 sampai dengan 1 ditiap titik data [8].

Dalam penentuan cluster nasabah pada BMT XXX dilakukan dengan model RFM (Recency, Frequency, dan Monetary) dari data transaksi penabungan. Recency merupakan jarak dari 
terakhir transaksi dengan pengambilan data, frequency tingkat keseringan nasabah melakukan transaksi, Monetary jumlah nominal transaksi nasabah dalam melakukan penabungan [9] Dari permasalahan yang dialami oleh BMT XXX mengenai pengelompokkan nasabah yang potensial maka akan dilakukan penelitian deangan judul Segementasi nasabah tabungan pada BMT XXX dengan metode Fuzzy C Means dan model RFM untuk. Fuzzy C Menas dapat menentukan jumlah cluster yang akan dibentuk, tujuan dari penelitian ini adalah mengkaji unjuk kerja fuzzy C Means dalam pembentukan cluster nasabah potensial, sehingga dapat digunakan sebagai bahan pertimbangan untuk pengambilan keputusan manajemen.

\section{Metode Penelitian}

Tahapan penelitian yang dilakukan menggunakan metode eksperimen dengan tahapan peneiltian sebagai berikut:

\begin{tabular}{|l|l|}
\hline 1 & -Pengumpulan data \\
\hline 2 & -Pengolahan data \\
\hline 3 & $\cdot$ Metode yang diusulkan \\
\hline 4 & $\cdot$ Eksperimen metode \\
\hline 5 & -Validasi hasil atau pengujian \\
\hline
\end{tabular}

\section{Hasil dan Pembahasan}

\subsection{Pengumpulan data}

Pada tahap ini melakukan pengumpulan data transaksi penabungan pada tahun 2019 dari bulan januari sampai dengan bulan desember. Terdapat 4.882 nasabah dengan jumlah transaksi 35.517 untuk setoran.

\subsection{Pengolahan awal data}

Dari transaksi data setoran yang diperoleh sebanyak 35.517 transakasi, dilakukan pengolahan awal dengan mengelompokkan per nasabah. Dari pengelompokkan nasabah diperoleh sebanyak 1.392 nasabah.yang aktif melakukan penabungan. Untuk mengetahui segementasi nasabah ini menggnuakan model RFM (Recency, Frequency, dan Monetary).
Recency interval antara penabungan terakhir dengan pengambilan data. Pengambilan data dilakukan pada 1 Januari 2020 dan dinyatakan dalam satuan hari. Untuk perhitungan frequency dengan menjumlahkan transaksi penabungan untuk setiap nasabah dalam 1 tahun. Sedangkan monetary merupakan jumlah saldo setiap nasabah sampai di tgl 31 Desember 2019. Data nasabah tersebut dibagi menjadi 6 kelompok dengan rincian sebagai berikut:

Tabel 1. Karakter pelanggan berdasrkan nilai RFM

\begin{tabular}{|c|c|}
\hline Keterangan nasabah & Karakteristik nasabah \\
\hline Superstar & $\begin{array}{l}\text { 1. Pelanggan dengan loyalitas yang tinggi } \\
\text { 2. Mempunyai nilai Monetary yang paling } \\
\text { tinggi } \\
\text { 3. Mempunyai Frequency yang paling tinggi } \\
\text { 4. Mempunyai transaksi paling tinggi }\end{array}$ \\
\hline Golden & $\begin{array}{l}\text { 1. Mempunyai nilai Monetary tertinggi yang } \\
\text { ke dua } \\
\text { 2. Frequency yang tinggi } \\
\text { 3. Mempunyai rata-rata transaksi }\end{array}$ \\
\hline Typical Customoer & $\begin{array}{l}\text { Mempunyai rata-rata nilai Monetary dan rata- } \\
\text { rata transaksi }\end{array}$ \\
\hline Occantional customer & $\begin{array}{l}\text { 1. Nilai monetary terendah kedua setelah } \\
\text { golden customer } \\
\text { 2. Nilai recency paling rendah } \\
\text { 3. Transaksi paling tinggi }\end{array}$ \\
\hline Everyday shopper & $\begin{array}{l}\text { 1. Memiliki peningkatan transaksi } \\
\text { 2. Transaksi yang paling rendah } \\
\text { 3. Mempunyai nilai monetary sedang sampai } \\
\text { rendah }\end{array}$ \\
\hline Dormant customer & $\begin{array}{l}\text { 1. Mempunyai frekuensi dan monetary yang } \\
\text { paling rendah } \\
\text { 2. Nilai recency yang paling rendah }\end{array}$ \\
\hline
\end{tabular}

\subsection{Metode yang diusulkan}

Metode yang diusulkan adalah Fuzzy C Means, Fuzzy $C$ Means merupakan teknik penglompokkan data, derajat keanggotaan menentukan suatu kelompok (cluster). Setiap objek dapat menjadi anggota dari beberapa cluster. Fuzzy $C$ Means dapat memiliki kemampuan pengelompokkan data yang lebih besar dan lebih kokoh pada data outlier. [10]. Algoritama

$$
J_{t}=\sum_{i=1}^{N} \sum_{j=1}^{C} \mu_{i j}^{m}\left\|x_{i}-C_{j}\right\|^{2}
$$

\section{Dimana:}

$m(m>1)$ adalah skalar yang disebut eksponen pembobotan dan mengontrol ketidakjelasan (fuzzyness) klaster, $m$ diatur ke nilai 2.00. 
$\mu_{i j}=$ derajat keanggotaan dari xi di dalam klaster j

$x_{i}$ : dimensi data

$c_{j}$ : dimensi pusat klaster

$\left\|x_{i}-c_{j}\right\|:$ Euclidean distance antara xi dan

$\mathrm{cj}$

Secara umum, pengukuran jarak titik data

(xi) ke pusat klaster (cj) didasarkan pada pengukuran kemiripan.Salah satu pengukuran yang digunakan adalah Euclidean distance yang ditunjukkan pada persamaan (2)

$$
\left\|x_{i}-c_{j}\right\|=\sqrt{\sum_{j=1}^{c}\left(x_{i}-c_{j}\right)^{2}}
$$

Algoritma Fuzzy c-means ditunjukkan dalam Gambar 1.

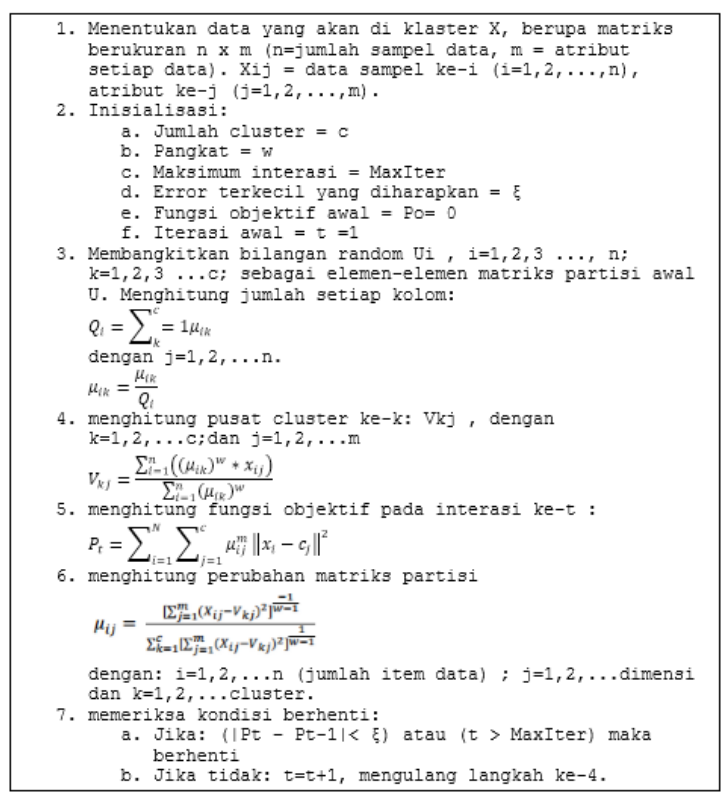

Gambar 1. Algoritma Fuzzy C-Means

\subsection{Eksperimen}

Hasil perhitungan fuzzy c-means untuk data nasabah dapat disajikan pada tabel 1 sebagai berikut:
Tabel 2. Data nasabah dengan perhitungan fuzzy C means

\begin{tabular}{|c|c|c|c|c|c|c|}
\hline No & Cluster 1 & Cluster 2 & Cluster 3 & Cluster 4 & Cluster 5 & Cluster 6 \\
\hline 1 & 0.002526 & 0.920696 & 0.003191 & 0.052472 & 0.013193 & 0.007922 \\
\hline 2 & 0.826907 & 0.022315 & 0.013763 & 0.034979 & 0.018818 & 0.083217 \\
\hline 3 & 0.013573 & 0.058544 & 0.006792 & 0.807065 & 0.019401 & 0.094626 \\
\hline 4 & 0.002185 & 0.029635 & 0.001658 & 0.9508 & 0.005621 & 0.010101 \\
\hline 5 & 0.004619 & 0.079087 & 0.003692 & 0.879708 & 0.012764 & 0.02013 \\
\hline$\ldots$ & $\ldots$ & $\ldots$ & $\ldots$ & $\ldots$ & $\ldots$ & $\ldots$ \\
\hline 1388 & 0.005697 & 0.864857 & 0.007871 & 0.074699 & 0.030819 & 0.016056 \\
\hline 1389 & 0.0059 & 0.861185 & 0.008206 & 0.076046 & 0.032109 & 0.016554 \\
\hline 1390 & 0.005697 & 0.864859 & 0.007871 & 0.074698 & 0.030819 & 0.016056 \\
\hline 1391 & 0.0059 & 0.861185 & 0.008206 & 0.076046 & 0.032109 & 0.016554 \\
\hline 1392 & 0.0059 & 0.861186 & 0.008206 & 0.076045 & 0.032109 & 0.016554 \\
\hline 1388 & 0.005697 & 0.864857 & 0.007871 & 0.074699 & 0.030819 & 0.016056 \\
\hline
\end{tabular}

Untuk menghitung RFM score, lakukan pembobotan untuk variabel recency, frequency dan monetary dengan cara mengambil nilai quartil 1, quartil2, quartil3 dan quartil4.

Tabel 3. Pembobotan Variabel

\begin{tabular}{|l|l|l|l|l|l|}
\hline \multicolumn{2}{|l|}{ Frequency } & \multicolumn{2}{l|}{ Recency } & \multicolumn{2}{l|}{ Monetary } \\
\hline Q1 & 2 & Q1 & 9 & Q1 & 1433599 \\
\hline Q2 & 8 & Q2 & 58 & Q2 & 7720008 \\
\hline Q3 & 24 & Q3 & 177 & Q3 & 39659943 \\
\hline
\end{tabular}

Lakukan pembobotan variabel rfm dengan rule sebagai berikut

\section{Recency}

IF Recency $>177=1$

IF Recency $>58$ dan Recency $<=177=2$

IF Recency $>9$ dan Recency $<=58=3$

IF Recency $<=9=4$

Frequency

IF Frequency $<2=1$

IF Frequency $>=2$ dan Frequency $<8=2$

IF Frequency $>=8$ dan Frequency $<24=3$

IF Frequency $>=24=4$

Monetary

IF Monetary < 1433599 = 1

IF Monetary >= 1433599 dan Monetary <

$7720008=2$

IF Monetary >= 7720008 dan Monetary < $39659943=3$

IF Monetary $>=39659943=4$

Setelah rule di buat, akan dihitung menggunakan rumus

$$
\begin{aligned}
\text { RFM score }= & (100 * \text { nilai recency }) \\
& +(10 * \text { nilai frequency }) \\
& + \text { nilai monetary }
\end{aligned}
$$

Setelah dilakukan scoring mengikuti rule diatas akan didapatkan hasil sebagai berikut 
Tabel 4. Scoring Rule RFM

\begin{tabular}{|l|l|l|l|l|l|}
\hline No & Klaster & Score R & Score $\mathrm{F}$ & Score M & Total Score \\
\hline 1 & 2 & 3 & 2 & 3 & 323 \\
\hline 2 & 1 & 1 & 1 & 3 & 113 \\
\hline 3 & 4 & 2 & 1 & 1 & 211 \\
\hline 4 & 4 & 2 & 2 & 3 & 223 \\
\hline 5 & 2 & 2 & 2 & 3 & 223 \\
\hline & $\ldots$ & $\ldots$ & $\ldots$ & $\ldots$ & $\ldots$ \\
\hline 1388 & 2 & 4 & 1 & 1 & 411 \\
\hline 1389 & 2 & 4 & 1 & 1 & 411 \\
\hline 1390 & 2 & 4 & 1 & 1 & 411 \\
\hline 1391 & 2 & 4 & 1 & 1 & 411 \\
\hline 1392 & 2 & 4 & 1 & 1 & 411 \\
\hline
\end{tabular}

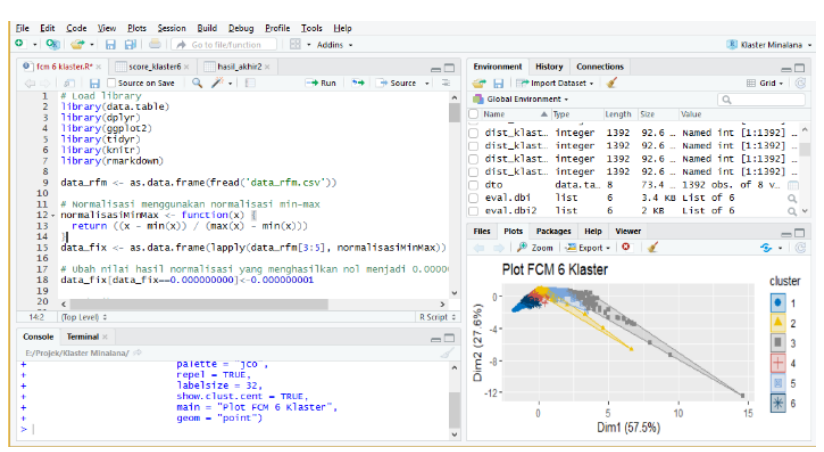

Gambar 2 Eksperimen dengan Tools RStudio 1.1.463 dengan versi bahasa $\mathrm{R}-4.0 .3$

3.5 Validasi Hasil dan evaluasi

Untuk pengujian menggunakan Bavies Bouldin Index. Dengan mimiliki dasar dalam menghitung similarity antar klaster.

$$
\begin{aligned}
& D B=\frac{1}{n_{c}} \sum_{i=1}^{n_{c}} R_{i} \\
& R_{i}=\max _{j=1 . . n c, i \neq j}\left(R_{i j}\right), i=1 . . n_{c} \\
& R_{i j}=\frac{S_{i}+S_{j}}{d_{i j}}
\end{aligned}
$$

$S_{i}=$ adalah rata-rata jarak objek seluruh klaster i dengan pusatnya.

$d_{i j}=$ adalah jarak pusat klaster i dan pusat klaster $\mathrm{j}$

Tabel 5. Perbandingan hasil pengujian Davies Bouldin Index

\begin{tabular}{|l|l|}
\hline Jumlah Klaster & $\begin{array}{l}\text { Davies Bouldin } \\
\text { Index }\end{array}$ \\
\hline 6 & 0.464 \\
\hline 7 & 0.466 \\
\hline
\end{tabular}

Cluster yang baik adalah dengan mempunyai nilai davies Boldin Index yang kecil [11], untuk mengoptimalkan klaster maka dicari dengan nilai davies Boldin Index paling kecil.

Tabel 6. Summary Hasil Segmentasi berdasarkan RFM

\begin{tabular}{|l|l|l|l|l|l|l|}
\hline Cluster & $\begin{array}{l}\text { Jumlah } \\
\text { Nasabah }\end{array}$ & Mean & Avg R & Avg F & Avg M & RFM Score \\
\hline c1 & 217 & 0.8313105 & 296.935484 & 4.345 & 6732443 & $111-144$ \\
\hline c2 & 462 & 0.8299806 & 16.939394 & 16.939 & 75893024 & $311-344$ \\
\hline c3 & 79 & 0.7643223 & 3.860759 & 164.063 & 1041830754 & $344-444$ \\
\hline c4 & 271 & 0.7613943 & 87.088561 & 8.490 & 25737310 & $211-344$ \\
\hline c5 & 124 & 0.7475178 & 9.854839 & 85.362 & 129386382 & $243-444$ \\
\hline c6 & 239 & 0.8014585 & 181.698745 & 6.527 & 16678581 & $111-243$ \\
\hline
\end{tabular}

Evaluasi dari metode fuzzy $C$ means dengan pengujian davies bouldin index, dapat dihasilkan 6 kelompok atau 6 cluster nasabah. Maka dari itu nasabah dikelompokkan seperti tabel berikut:

Tabel 7. jumlah nasabah dengan karakteristik berdasrakan cluster

\begin{tabular}{|l|l|l|}
\hline Kelas nasabah & Cluster nasabah & Jumlah nasabah \\
\hline Superstar & $\mathrm{C} 3$ & 79 \\
\hline Golden & $\mathrm{C} 2$ & 462 \\
\hline Typical Customoer & $\mathrm{C} 5$ & 124 \\
\hline Occantional customer & $\mathrm{C} 4$ & 271 \\
\hline Everyday shopper & $\mathrm{C} 6$ & 239 \\
\hline Dormant customer & $\mathrm{C} 1$ & 217 \\
\hline
\end{tabular}

\section{Kesimpulan}

Dari penelitian ini dapat disimpulkan adalah sebagai berikut:

1. Pengelompokkan nasabah pada BMT XXX didapatkan 6 cluster yang paling optimal, dengan pengujian davies bouldin index.

2. Total nasabah yang aktif di tahun 2019 adalah 1.392 nasabah. Dari hasil perhitunag fuzzy $C$ means, cluster Jumlah nasabah yang potensial 665 nasabah, dari kelas nasabah (superstar, golden, typical customer). Sedangkan jumlah nasabah yang kurang potensial 727 nasabah dari kelas (occational cutomer, everyday shopper, dormant cutomer).

3. Segementasi nasabah tersebut dapat digunakan oleh BMT XXX untuk melakukan strategi marketing untuk meningkatkan pelanggan agar selalu aktif dalam menabung. 


\section{Daftar Pustaka}

[1] V. Migueis, A. Comanho dan J. F. Cunha, "Customer data mining for life style segmentation," Expert syst appl, vol. 39, no. 10, pp. 9359-9366, 2012.

[2] E. B. Ardiana, I. Soesanti dan A. E. Permanasari, "Analisis segmentasi pelanggan menggunakan kombinasi RFM model dan teknik clustering," JUTEI, vol. 2, no. 1, p. 23, 2018.

[3] R. R. Putra dan C. Wadisman, "Implementasi data mining pemilihan pelanggan potensial menggunakan algoritma K-Means," Journal of information technology and Computer Science, vol. 1, no. 1, p. 72, 2018.

[4] T. Hardiani, "Segmentasi Nasabah Simpanan Menggunakan Fuzzy C Means dan Fuzzy RFM pada BMT XYZ," Nero, vol. 3, no. 3, pp. 185-192, 2018.

[5] P.on dan R.Banks, "International Journal of Management Research and Review Coustomer Realationship Management," the study of Customer, vol. 4, no. 1, pp. 2739, 2014.

[6] A. h. Lubis, "Model segementasi pelanggan dengan kernel $\mathrm{K}$ means clustering berbasis customer relationship management," Sinkron, vol. 1, no. 1, pp. 36-41, 2016.

[7] I. Sumadikarta dan E. Abeiza, "Penerapan algoritma $\mathrm{k}$ means pada data mining untuk memilih produk dan pelanggan potensial," satya informatika, vol. 1, no. 1, pp. 12-22, 2014.

[8] D. Astria dan Suprayogi, "Penerapan algoritam fuzzy c means untuk clustering pelanggan pada $\mathrm{Cv}$. Mataram jaya bawen," eksplora informatika, vol. 6, no. 2, pp. 169178, 2017.

[9] N. R. Syarif dan Windarto, "Aplikasi data mining dengan menggunakan algoritma fuzzy C means dan Metode RFM untuk pengelompokkan pelanggan pada PT Eka Cipta rasa," Skanika, vol. 1, no. 3, pp. 10931099, 2018.

[10] N. 1. G. P. Suwirmayanti, "Penerapan Metode Fuzzy C means untuk pengelompokkan data kredit," STMIK ponti, pp. 390-395, 2018.

[11] Qiao, Haiyan dan Brondon, "A data Clustering Tool with Cluster Validity Indices," International Conference on Computing Engineering and Infromation IEEE, 2009. 